\title{
Timing of treatment initiation in West's syndrome
}

\author{
M.E. Farnosova, T.F. Zharikova, R.G. Gamirova* and S.N. Sivkova \\ Kazan Federal University, Department of Basic and Clinical Pharmacology, Kazan, Russia Kazan \\ Municipal Children’s Hospital № 8, Kazan, Russia
}

*Corresponding author. E-mail: r-gamirov@mail.ru

BACKGROUND: Infantile spasms (called the West's Syndrome) represent a severe epileptic syndrome which is characterized by a peculiar type of epileptic seizures, spasms, and by electroencephalographic (EEG) abnormalities often called hypsarrhythmia [1]. Infantile spasms are usually resistant to conventional antiepileptic drugs (AEDs) and adrenocorticotrophic hormone (the synthetic analog tetracosactide) has been the preferred treatment since 1958. The evidence for other antiepileptic drugs is extremely limited compared with vigabatrin. Most recent studies deal only with short-term drug effects and fail to use clinically meaningful outcome measures. Furthermore, attention needs to be given to dropout rates in the studies, because some studies include a majority of patients with primarily favourable outcome [2]. Effective treatment is now defined as complete cessation of the spasms plus abolition of hypsarrhythmia ('all-or-none response') [3]. So far there has been no consensus on dosage or duration of therapy, influence of early initiation of treatment on the outcomes of West syndrome therapy.

OBJECTIVE: To assess if the timing of treatment initiation (early or late) influences the outcomes of West syndrome therapy.

METHODS: We conducted a retrospective observational study at the Kazan Municipal children's hospital № 8 among children with West syndrome. When treatment with tetracosactide (synacthen depot) or antiepileptic drugs was initiated within 1 month after the onset of seizures we defined it as "early treatment initiation". If this therapy was started after 1 month of the onset of seizures, we defined it as "late treatment initiation". We used was the number of seizure-free patients after 2 months, 6 months and 1 year from the start of the treatment as the favorable outcome measure. We calculated risk ratios (RR) for favorable outcomes and their confidence intervals (CI) using RevMan 5.3 Software, comparing outcomes of early and late treatments.

RESULTS: We analyzed medical records of 150 children with infantile spasms. The diagnosis of West syndrome was confirmed by video-EEG-monitoring findings and by clinical examinations. Gender distribution of patients with West syndrome was with some predominance of boys: 93 boys $(62 \%)$ and 57 girls (38\%), which corresponded to the published literature data. The duration of follow-up was at least 3.5 years. The mean age of patients at the time of analysis was 6 years, from 4 years $(\mathrm{min})$ to 14 years 5 months (max). We divided all of the children into four groups:

Group IA - early treatment initiation - included children who were started on tetracosactide within 1 month from the onset of seizures ( 30 patients).

Group IB - late treatment initiation - included children who were started on tetracosactide after 1 month of the onset of seizures (60 patients). 
Group IIA - early treatment initiation - included children who were started on antiepileptic drugs as mono- or polytherapy within 1 month from the onset of seizures (22 patients).

Group IIB - late treatment initiation - included children who were started on antiepileptic drugs after 1 month of the onset of seizures (38 patients).

Children in all groups were similar with respect to age, sex, severity of the disease. Effectiveness of tetracosactide in the group IA and in the group IB at 2 months, 6 months and 1 year of follow up (from the beginning of treatment) was comparable: $\mathrm{RR}=1.00 ; 95 \% \mathrm{CI}[0.79,1.27] ; \mathrm{P}=1,00 ; \mathrm{RR}=0.96 ; 95 \%$ CI $[0.74,1.24] ; \mathrm{P}=0,74 ; \mathrm{RR}=1.00 ; 95 \%$ CI $[0.75,1.33] ; \mathrm{P}=1,00 ;$ respectively

Comparative analysis of the effectiveness of treatment with antiepileptic drugs (without tetracosactide) at 2 months, 6 months and 1 year of follow up (from the initiation of treatment) demonstrated that the number of patients achieving clinical remission was higher in the group IIA, in which the therapy was started within 1 month of the onset of the disease versus the "late treatment initiation" group IIB: RR= $2.76 ; 95 \%$ CI $[1.03,7.41] ; \mathrm{P}=0,04 ; \mathrm{RR}=1.62 ; 95 \% \mathrm{CI}[1.01,2.59] ; \mathrm{P}=0,04 ; \mathrm{RR}=1.37 ; 95 \% \mathrm{CI}[1.02$, $1.84] ; \mathrm{P}=0,04$; respectively.

CONCLUSIONS: The timing of initiation of tetracosactide therapy did not influence the outcomes of West syndrome therapy. The early initiation of treatment with antiepileptic drugs (but without tetracosactide) resulted in a greater number of patients achieving remission, compared with late treatment initiation.

Keywords: West's syndrome, tetracosactide

Conflict of interest statement: Authors declare that there is no conflict of interest.

\section{References}

[1] Hancock E, Osborne J, Edwards S. Treatment of infantile spasms. Cochrane Database of Systematic Reviews [Internet] 2013 [cited 2013 JUN 5]. Available from: http://www.mrw.interscience.wiley.com/cochrane/clsysrev/articles/CD001770/ frame.html

[2] Mackay, M.T., Weiss, S.K., Adams-Webber, T., Ashwal, S., Stephens, D., Ballaban-Gill, K. et al, Practice parameter: medical treatment of infantile spasms: report of the American Academy of Neurology and the Child Neurology Society. Neurology. 2004;62:1668-1681.

[3] Riikonen R. Recent advances in the pharmacotherapy of infantile spasms. CNS Drugs. 2014 Apr;28(4):279-90. doi: 10.1007/s40263-014-0139-5 